\title{
WATER SUPPLY AND POLLUTION CONTROL ASPECTS OF URBANIZATION
}

\author{
EDWARD H. BRYAN*
}

\section{INTRODUCTION}

The practice of the profession of civil engineering has from its inception been intimately associated and concerned with technical problems resulting from and relating to urbanization. The practice of civil engineering is concerned with preliminary surveys of needs, design, construction, operation and maintenance of "works" involving transportation (including rail, highway, pipe line, airports, waterways and harbor facilities), storm and sanitary drainage, water supply and treatment, sanitation, waste treatment and disposal and such important ancillary functions to the above as soils and foundations, hydraulics, engineering mechanics, measurements and structural design. The civil engineer is frequently involved in municipal planning and management by virtue of his competence in the composite technology relating to urbanization.

Although the civil engineer is committed to expressing his technical competence in the area of urban development, civil engineering leadership is growing increasingly concerned about the profession's apparently declining role in the areas of urban planning and building technology. ${ }^{1}$ Architects, social scientists, economists, political scientists, lawyers, and public administrators are progressively exerting greater leadership in urban development. The ability of technology to provide the essential services in response to patterns of urban development emerging from this leadership is generally assumed. The challenges offered in the analysis, evaluation and development of solutions to the complex functional problems of urban development are great and are growing. The unfortunate consequence of preliminary neglect of technical constraints and alternatives in the community planning function is the lack of complete freedom in exploration of acceptable alternative plans for minimization of cost or for equal cost, maximization of return. The question of what constitutes the most appropriate background for leadership is not as important as is recognition of the importance of bringing to bear on the subject of urban planning all of the essential technical skills at a sufficiently early stage in the planning function to affect significantly the selection of alternative courses of action.

- B.S. 1949, M.S. 1950, Ph.D. 1954, University of Wisconsin. Professor of Civil Enginecring, Duke University. Registered Professional Engineer in Wisconsin since 1954. Member of the American Society of Civil Engineers, American Water Works Assocation, Water Pollution Control Federation, and the American Society for Engineering Education. Conference Chairman and Editor of the Proceedings of the Tenth and Thirteenth Southern Municipal and Industrial Waste Conferences. Contributor of papers to journals in the field of industrial waste treatment and water pollution control. Employed by the Dow Chemical Company from 1953 through 1960 in several capacitics relating to its corporate interests in water resources and pollution control.

${ }^{1}$ Wisley, The Civil Engineer in Urban Planning, Civil Engineering, Dec. 1964 . 
Although all engineering is basically involved in the continued reduction to practice of scientific discovery which must consider the application of discovery in terms of both technical practicability and relative economy, the civil engineer must frequently consider political reality, the social consequences of his works and have reasonable familiarity with the legal framework within which he must operate. In the words of the Task Committee on Professional Education of the American Society of Civil Engineers," "Cutting across every sphere of human activity, it [civil engineering] is more intimately associated with the business, health and wellbeing of the people than is any other branch of the engineering profession."

Increasing needs for specialization to interpret skillfully the expanding advances in scientific discovery coupled with the need for better understanding of their application in terms of economic feasibility require the continued attraction of capable young people into the profession. The means of attracting such individuals is a continuing concern of the practicing civil engineer. Once attracted, the young engineer's motivation must continue to be cultivated by his participation at all stages of the projects in which he will exercise his technical skills, including leadership when appropriate.

Of all technical aspects of urbanization within the domain and of concern to the civil engineer, none better illustrates the interrelationship among disciplines than water resources, cutting across the boundaries of the biological, chemical and physical sciences. The very need to consider both water supply and pollution control as a single subject is illustrative of the accelerating demand placed upon our resources by urbanization. In the not too distant past, it was usual practice to consider these as legitimately separate problems although in fact they never were. A clear understanding of the source of our water supply and its destiny following use is basic to an understanding of this relationship.

\section{The Hydrologic Cycle}

The term "hydrologic cycle" is used to characterize the movement of water between its two major reservoirs, namely, the oceans, where water is present in its liquid state, and the earth's atmosphere, where it is present in its gaseous or vapor state. Approximately 95,000 cubic miles of water are evaporated each year from the oceans and land surfaces of the earth exactly equaling the annual precipitation of moisture from the atmosphere. Of this total precipitation, approximately 24,000 cubic miles fall on land surfaces. ${ }^{3}$ The driving force for maintaining the cyclic movement of water between these reservoirs is solar energy. Both the movement of moisture into the atmosphere and the pattern of its precipitation are influenced by major and minor variations in the amount of solar energy received over the earth's

${ }^{2}$ American Soc'y of Civil Engineers, Report of Task Committee on Professional Education, Civil Engineering, Feb. 1958 .

${ }^{3}$ Ackermann, Coleman \& Ogrosky, Where We Get Our Water, WATER-THE YeArbook of AgRICULTURE 4I (U.S. Dep't of Agriculture, 1955). 
surface. Weather patterns which determine the distribution and form of precipitation are a function of the earth's orientation in space with respect to the sun and the complex relationship between the earth's rotation, the movement of the atmosphere, and the geographical configuration of the earth's surface. Over any extended period of time, all of these factors bear a relatively constant relationship for a specific area on the earth and at present are uncontrollable.

Water precipitating over and reaching land surfaces moves downward and laterally through natural and artificial channels under influence of gravity toward the ocean reservoir. Water is intercepted during this movement toward the oceans by land plants and animals. It may be consumed in part or used without being consumed and returned to the water-courses for continuation of its movement to the seas. During this movement, the water may be used and re-used many times, undergoing some loss in quantity by evaporation and transpiration and some loss in quality after each use and being subjected to conditions which may result in all possible combinations of natural and artificial improvement and degradation in quality. During its movement over the land a portion of the water seeps into the land. That which is not used by vegetation becomes part of the ground water reservoir underlying the land, where it may be trapped or continue its lateral movement toward the seas underground at a pace governed by the nature and structure of its path.

Water has played a major role, sometimes unobtrusively, in the development of our civilizations. Aside from the obvious, natural sources of water such as intercepted rain water, streams, lakes and springs, the earliest method of obtaining water was probably by the digging of wells. Wells which were used during their construction exist in the vicinity of the pyramids. Either in historical account or in physical evidence today are references to and/or the remains of such works in ancient Greece, Assyria, Persia, India, and China. Remains of the aqueducts serving ancient Rome are still extant. They represent the ancient counterpart of our quest for pure water, that is, the continued need to bring water from ever more remote locations to counteract the pollutional effect of civilization on local water resources. In light of present knowledge, it is as reasonable to account for the nomadic tendencies of our ancestors on the basis of their desire to move away from accumulations of filth as upon their pursuit of "game." An adequate supply of pure (or purificable) water and an adequately engineered system for disposal of wastes are as indispensable to our present civilization as they were in the past. Our current degree of freedom almost to ignore the defilement of water was made possible by nineteenth century discoveries including the nature of disease, the causative relationship between ingestion of contaminated water and incidence of certain diseases, the role of contaminated water in the spread of disease to epidemic proportions and the consequent development of water treatment technology aimed at converting water of poor quality into usable public water supplies. Without these scientific and technological discoveries, population growth and urban development would likely 
have been kept in natural check by epidemics of waterborne diseases such as cholera, typhoid fever, and the dysenteries.

Simultaneously with the emergence of this new knowledge and its application came the development of methods for converting stored energy in the form of fossil fuels to useful purposes. Hydroelectric power and more intensive utilization of gravitation to transport water great distances were made possible on large scales by the development of mechanical equipment for the construction of large structures to impound, pump and conduct water long distances to the sites of its intended use. The possible supplementation of hydrologic-cycle water with converted saline water and its transmission over long distances will be strongly influenced by the discovery of nuclear energy and development of technology to release this energy usefully. The "ultimate" (limitless) source of power, namely, that derived from fusion, is today only a technological dream.

Ideally, water should arrive at the position of its use in adequate quantity at the correct time and be of quality satisfactory for its intended use. Urbanization in a location where local intercepted water to support this development is lacking must bear the cost of importation of sufficient water. An excellent example of the current scale of such an operation is the planned transfer of water from northern California where water is now in excess of current demands to southern California where the needs of urbanization long ago exceeded the available local water supply. The projected cost for this engineering project is in excess of four billion dollars. ${ }^{4}$ Its aim is to supplement the Colorado River water presently used in support of the rapidly urbanizing Metropolitan Water District of Southern California. In I963, deliveries of Colorado River water to the District exceeded one billion gallons per day. Despite a "partially adverse" decision of the United States Supreme Court relevant to Colorado River water rights, the district is hopeful of ultimately assuring itself of 4.4 billion gallons per day from this source. Colorado River water is moved from Lake Mead through a system of tunnels, siphons, and canals necessitating a pumping head of over r 600 feet. The total energy used for operation of this system during $1962-63$ was 2.2 billion kilowatt hours, principally obtained from the operation of the hydroelectric plants at Hoover and Parker dams. The 242 miles of the main aqueduct consist of ninety-two miles of tunnels, sixteen feet in diameter, fifty-five miles of sixteen-foot diameter concrete conduits, sixty-three miles of concrete-lined and one mile of unlined canals, and twenty-nine miles of siphons. The cost of the main aqueduct and the distribution system alone has almost reached 500 million dollars with an annual operating expense approaching twenty million dollars.

Expenditure of resources for transfer of water may increase the cost of water to in excess of that which was experienced in development of the local source. This has been more economical than processing of "used" local water for reuse. The alternatives involve an economic choice. The political and legal problems of

\footnotetext{
‘ The Metropolitan Water District of Southern California, Twenty-Fifth Ann. Rep. (ig63).
} 
diverting water from its natural channels within a single political subdivision, as for example, the state of California, are minor in comparison with the political and economic problems involved in diversion of water across major political boundaries. Fundamental decisions must be made with regard to existing and future water rights. Development along natural channels must be balanced against demands for water from existing and projected urban areas. These may involve interstate (California versus Arizona), interregional (upper versus lower Colorado River basins), and international (United States versus Mexico) interests.

Although to some extent man has wrestled with these problems since his early social development, it is only relatively recently that the fixed amount of this resource has been subjected to such intense utilization. This has resulted from at least three interrelated trends, namely, the increase in sheer numbers of individuals, their increasing concentration in urbanized areas, and the gradually increasing use of water on a per capita basis. The latter is directly related to industrialization with its almost insatiable thirst for water to produce goods demanded by ever-

TABLE I

\section{IndUStrial Water Consumption}

\section{Product}

Alcohol, industrial

Ammonia, synthetic

Beer

Bread

Canning of foods

Carbon dioxide

Caustic soda

Charcoal \& wood chemicals

Coal washing

Dairy products

Hospitals

Hotels

Hydrogen

Lactose (milk sugar)

Launderies

Meat packing

Phosphoric acid

Portland cement

Pulp and paper

Rayon

Soap

Steel

Sugar production and refining
Water Required Per Unit of Product

I20 gal. per gal., Ioo proof

$3 x, 000$ gal. per ton liquid ammonia

470 gal. per barrel

500-r,000 gal. per ton

300-16,000 gal. per case No. 2 cans

23,000 gal. per ton

r8,000-2r,000 gal. per ton

65,000 gal. per ton

r25 gal. per ton

4,000-5,000 gal. per ton butter or cheese

up to $35^{\circ}$ gal. per day per bed

300-525 gal. per day per room

660,000 gal. per ton

220,000 gal. per ton

ro,000 gal. per ton

55,000 gal. per roo hog units

75,000 gal. per ton

$75^{\circ}$ gal. per ton

50,000-150,000 gal. per ton

200,000 gal. per ton

500 gal. per ton

$20,000-35,000$ gal. per ton

up to 25,000 gal. per ton

Source: Manual on Industrual Water and in Industrial Wastewater (A.S.T.M. Pub. No. 148-D)

(2d ed. I959). 
increasing numbers of individuals who in turn are ever demanding the use and consumption of more goods per capita. Some insight into the industrial thirst for water may be gained by observation of the data in table one, which summarizes water needs for selected industrial products. These may be overlooked in a casual analysis of our needs for water, but they are as real as our more personal familiarity with the use of water in our daily activities.

Much progress has been made, and will continue to be made, in reducing the amount of water needed for industrial production. Although the water is not actually consumed, its use results in degradation of quality. This degradation may consist of an increase in concentration of soluble organic or inorganic substances, addition of potentially toxic chemicals, addition of substances in suspension or colloidal dispersion which affect the clarity and color of the water or simply increase its temperature. It is almost axiomatic that any use of water will have some effect on its physical, chemical, or biological quality.

Extensive reuse of water within manufacturing plants is a growing trend. Future demands on our total water resources will require maximum utilization of water because of limitations on the supply. The consequence of extensive reuse will be water, when it is finally discharged to receiving streams, of increasingly poorer quality which will necessitate treatment to an ever increasing degree prior to its placement in a receiving stream. Both conversion to extensive recirculation and thorough treatment prior to discharge to receiving streams will be ever more costly. The economic burden of industrial waste treatment must either be borne by the consumers or by those benefiting either directly or indirectly from the improvement in the region's water resources.

\section{Water Resources-Supply and Demand}

Until recently, urbanization has been largely accomplished without advance consideration for the water supply necessary to support each increment of growth. Each increment of Iooo people requires the runoff resulting from precipitation over 500 acres of land. As a consequence, municipalities have been forced to go greater distances from centers of urbanization to obtain adequate supplies and have found the unit cost for treatment of these supplies has increased because of their degrading quality. Water shortages in the past have been temporarily solved by rationing existing supplies until more could be brought to the site of its need. All adjoining centers of urbanization will be in direct competition with each other in their quest for more water long before they merge into a continuous metropolis.

The average daily precipitation on the continental United States has been estimated at 4300 billion gallons. Of this, approximately seventy per cent either evaporates or is transpired by natural vegetation and non-irrigated crops, leaving an average balance of $x 300$ billion gallons per day. The generally accepted ultimate level of development, in recognition of the impracticability of completely impounding all 
flood flows for gradual release to our streams to maintain this average level, is in the neighborhood of fifty per cent. Assuming maximum development of all available reservoir sites to be possible, only $65^{\circ}$ billion gallons per day of our water supply is capable of replenishment. It is, of course, unlikely that all sites will be utilized. Reservoir capacities will continue to diminish as a result of the gradual displacement of storage space for water in the reservoirs by silt washed from the land.

The water resource in terms of quantity is truly inexhaustible provided the quality of wastewater is sufficiently improved prior to its return to our lakes and streams to keep these waterways in satisfactory condition and to enable the downstream user to withdraw sufficient water of satisfactory quality for his intended use. This intended use may now require that he treat or condition a portion or all of the water withdrawn to make it completely satisfactory, but the quality of his raw supply must at least be technically and economically possible to treat. The need to treat water prior to use and the extent to which treatment is necessary can only increase in the future.

There would, of course, be no problem in connection with water resources if wastewater could be economically treated to remove all pollutional characteristics acquired through use. On the assumption that such processes could be developed and would be sustained by economic considerations, it would only be necessary to charge a recirculating system with sufficient water to fill its distribution and collection components including suitable reservoirs to compensate for unequal rate of usage. Losses to such a recirculating system resulting from consumptive use and leakage would be made-up with "fresh" water and the system would be periodically enlarged to increase the purification and distribution capacity to compensate for increased rate of recirculation resulting from growth of demand. Such a system is technically possible today! However, it is only economically justifiable where economic considerations preclude a continuing supply of fresh water to compensate for that used as, for example, to satisfy the water requirements of individuals on extended journeys in space. Colonization on the moon will undoubtedly make extensive use of such recirculating systems as a more economical alternative to importation of the required water from earth. ${ }^{5}$ This is, however, an extreme example involving a clear economic choice. The on-the-surface wasteful practice of using a ton of water to carry away one pound of solids continues to pose an interesting challenge to engineers. Assuming the necessity of such a system, can the wastewaters be processed to the degree that recoverable water can be reused for all municipal purposes?

As is clear from a consideration of the hydrologic cycle, something short of direct recirculation is already in extensive practice. Although the presence of wastewaters from upstream urban areas is either known or suspected by many, few object.

'Lowe, Water Supply on the Moon, 53 J. AM. WATER Works Ass'N 9 (I96r). 
Dilution, elapsed time and human capacity for adjustment tend to dissipate aesthetic objections.

Hickman explored the possibility of utilizing distillation in a wastewater recovery cycle. $^{0}$ He concluded that it was technically feasible to produce potable water in large units for an expenditure of thirty kilowatt hours of power per one-thousand gallons. Even without distillation, direct recirculation has in a few instances been already tested. The experience of Chanute, Kansas, during a period of five months in $195^{6-57}$, during which time water was recycled through the city from eight to fifteen times, has become an almost "classic" citation." In reviewing the Chanute and other experiences, Berger concluded that, ${ }^{8}$

A combination of current sewage and water treatment processes should, therefore, not be considered adequate to convert sewage to safe drinking water. Total recovery of the pure water in municipal sewage will require a much better understanding of the microbial and chemical challenges involved.

Direct recirculation of water is already extensively practiced in industry. It is estimated that industry on the average uses its water twice, that is, of its total requirements, one-half comes from recirculation within the process or within the plant. Until now, this has been accomplished by recognizing differences between usefulness and quality requirements for water in successive processes and selecting the process order in accord with that of essential water quality or the regeneration of a particular water attribute and its return to the process. These systems have been successful to date, are growing in importance, and will continue to be a source of effective increase in our total water resources. However, it must be recognized that progressive degradation of water will occur in a recirculating system which will require the ultimate rejection of such water either continuously or gradually when its quality in the system reaches the intolerable level. The net effect of such recirculation and water conservation measures is to transfer the pollutional load to the next user via a natural stream which may not offer sufficient capacity for natural self-purification.

Of considerable interest is the current activity of the United States Department of the Interior in connection with desalinization. Processes for the conversion of waters containing salinity in excess of that tolerable for most purposes have been an economical method of supplying water in appropriate situations for many decades. The largest single plant known provides 3.5 million gallons daily on the Island of Aruba. Kuwait has five desalinization plants with a total capacity of 7.5 million gallons per day. The United States Office of Saline Water, operating during 1964 on

'Hickman, Role of Distillation in a Waste Water Recovery Cycle, $55 \mathrm{~J}$. AM. WATER Works Ass'N II 20 ( 1963$)$.

'Metzler et al., Emergency Use of Reclaimed Water for Potable Supply at Chanute, Kansas, 50 J. AM. WATER WORRS Ass'N IO2I (x958).

${ }^{8}$ Berger, Public Health Aspects of Water Reuse for Potable Supply, 52 J. AM. Water Works Ass'N 599 (Ig60). 
a budget of about twelve million dollars, has been investigating alternative processes by contracting for the construction and operation of sufficiently large-scale pilot plants to investigate comparative costs and to provide information for design of much larger plants. Progress cited recently by Secretary of Interior Udall ${ }^{0}$ indicates a reduction in costs of from $\$ 4-\$ 5$ per thousand gallons in 1952 to in the range of from \$1-\$1.25 per thousand gallons for the one-million-gallon-per-day plants operating at Freeport, Texas and San Diego, California. There is some indication that further enlargement of plants with the proper coupling of nuclear power generation to desalinization may reduce the costs to in the range of from twenty to twenty-five cents per thousand gallons. The projected size of such plants would be in the order of 500 to 800 million gallons per day. Plants of this size are considered technologically possible by 1975 .

Although desalinization will continue to play a significant and increasing role in providing water supplies in isolated situations where comparative economy or specific needs dictate such a choice, it will only be with the installation of the extremely large plants that desalinization will play a significant part in the total water resources picture. Despite current activity and consequent publicity the total present installed world-wide capacity of land-based desalinization plants is estimated to be fifty million gallons per day for sea water and twenty million gallons per day for inland brackish water conversion as compared with a present fresh water use of 300 billion gallons per day in the United States which has been projected to $5^{60}$ billion gallons per day in $1980 .^{10}$

Basically, the water supply for a community or industry becomes almost entirely the wastewater problem for its receiving environment. The receiving environment may be a lake, stream, subsurface formation, or the ocean. A most important functional role of water in community systems is as a transport medium. It is an economical and sanitary means of transporting wastes from their points of origin to a site for disposal. Although other methods of accomplishing this function are technically possible, the use of water as a carriage medium will be the rule rather than the exception in the foreseeable future.

During its origin, use and movement, water is in continuous contact with substances which continuously and progressively degrade its quality. The passage of water from the point of its introduction into the community distribution system to its return to the watercourse from which it may have been withdrawn is such a degrading contact. Even prior to the first of what could be a series of such contacts, water quality is affected by the atmosphere in which it precipitates, through which it falls, and its contact with the surface and subsurface of the land.

Our surface waters are absorbing vast quantities of new chemicals which are

${ }^{8}$ See Secretary of Interior Stewart Udall's report on desalinization progress during 1964, N.Y. Times, Dec. $27,1964, \S I$, pp. $r, 28$. (Ig6r).

${ }^{10}$ Wolman, Impact of Desalinization on the Water Economy, 53 J. AM. Water Works Ass'N I19 
the products of our expanding technology. Pesticides, herbicides, and synthetic detergents are those most frequently mentioned today. Rachel Carson's Silent Spring, ${ }^{11}$ published first as a series of articles in The New Yorker and distributed almost simultaneously in hard cover and paperback, has by virtue of its general accuracy and wide distribution contributed to public concern about the indiscriminate use of pesticides and herbicides.

The pollution of our air, itself a major problem relating to urbanization, has a significant and direct effect upon the quality of water resources. Internal combustion engines powering motor vehicles in ever-increasing numbers discharge their waste products into the atmosphere. Unburned hydrocarbons, oxides of nitrogen and residues of anti-knock additives, usually containing lead, are only a few examples of substances washed from the air by precipitation or settling to the earth's surface and washed from the surface to become part of the water pollutional burden even prior to other defilement. In the Los Angeles area, the combination of urbanization and topography have resulted in severe air pollution for more than a generation. Although fallout radiation is decreasing as a direct result of the current moratorium on nuclear bomb testing, it is expected that increased use of nuclear fuels for power generation, which will necessitate fuel reprocessing and its consequent waste products, will be a significant water resources problem in the future.

A typical community wastewater has in solution sufficient organic substances, in conjunction with normal biological life found in receiving streams, to require the dissolved oxygen found in thirty times as much stream water. This demand for oxygen, an attribute of wastewaters caused indirectly by the action of biochemical systems found in natural waters, is a major pollutional effect. In addition to this effect, the wastewater may contain bacteria, viruses, and other substances toxic to plant and animal life either living in the receiving waters or utilizing these waters for their body requirements. This waste may also contain a wide, almost infinite variety of substances in suspension and colloidal dispersion. What is most frustrating is the relatively minute concentration of these substances and the profound effect these small concentrations have on the receiving environment.

It is unfortunate that most natural factors tending to compensate for the potential pollutional effect of a waste on a particular receiving environment are unfavorable. As an example, consider the oxygen demand of a waste versus the oxygen supply of a receiving stream.

The oxygen resource of natural waters is the single most important factor in determination of their "health." However, oxygen is relatively insoluble in water. Its presence as only a twenty per cent component of the air places a further limitation upon its solubility in natural waters. To make matters still worse, the presence of other water soluble gases as are encountered in nature, such as carbon dioxide, further reduces the solubility of oxygen in water. Coupled with these

${ }^{11}$ Rachei Carson, Silent Spring (I962). 
natural limitations on the solubility of oxygen is the inverse relationship between the solubility of all gases and temperature. It is usually during low stream flow: that high atmospheric and water temperatures prevail. Biochemical activity tending to reduce oxygen levels in natural waters is accelerated at these higher temperatures. The net effect of these uncontrollable natural circumstances is an oxygen concentration in water at a level generally below eight parts per million during periods when low stream flows are being experienced and when temperatures favor accelerated utilization of this oxygen resource. As a result of reduced stream turbulence, reoxygenation of oxygen-depleted water is reduced by the act of impounding water to conserve excess flow.

Natural waters containing less than two parts per million of dissolved oxygen cannot support the various biological forms characteristic of unpolluted waters. An oxygen concentration of less than four parts per million on a continuing basis provides little tolerance for accidental further reduction without serious consequences. Fish, characteristic of unpolluted streams and lakes, require in excess of four parts per million.

Strong wastewaters in terms of their demand for oxygen are relatively pure, containing at least 99.9 per cent pure water. The remaining one tenth of one per cent ( $\mathrm{x}, 000$ parts per million) concentration of impurities in vast quantities of wastewater exerts profound effects on receiving streams. The pollutional effect of a waste can be reduced, but not normally eliminated by treatment. The problem with which the sanitary engineer is faced is the reduction of the pollution characteristics of a wastewater which initially is already more than 99.9 per cent purel His objective is to reduce the waste's pollutional characteristic by a sufficiently significant amount to permit disposal of the residue to a receiving stream without exceeding its capability to assimilate this pollutional load. The capacity of a stream to assimilate a waste is determined by characteristics of both the stream and the waste.

A treatment process which is ninety per cent efficient in removal of pollutional substances, the present limitation of general technical and economic capability, will still leave ten per cent. Using a waste containing only 500 parts per million of oxygen-demanding substances as an example, the residue or effluent after treatment may have an oxygen demand of fifty parts per million. Doubling the capital investment in this treatment plant may increase the total efficiency to perhaps ninetyfive to ninety-seven per cent. Even at this level of capability, we may still be imposing a greater load on the stream than it is capable of assimilating without a dilution factor of five times the volume of waste.

The self-purification tendencies of a stream, that is, its capability of assimilating pollution, is partly a function of time which in a stream is analogous to distance. During the progress of the water through successive intakes and outfalls of our urbanized areas, stream characteristics become progressively worse. What is additionally frustrating is that even if we were to consider the technical ideal of roo per cent 
removal of all organic pollutants, the residual soluble nutrient substances of no direct pollutional significance can exert a fertilization effect of a stimulatory nature on what might otherwise be a self-regulating system in biochemical balance. This may further result in the progressive degradation of our systems of natural and man-made reservoirs. This process of aging of lakes, known technically as eutrophication, is of great concern as we see its beginnings in massive reservoirs of fresh water, as for example, the Great Lakes. ${ }^{12}$

Stimulation of algal activity with its successive and progressively accelerating cycles of growth and decay, results in the production and destruction of organic matter at the expense of oxygen resources. The continuous cycling of nutrients can in itself progressively deteriorate these bodies of water in terms of their usefulness as water supplies or greatly increase the cost of treatment prior to use of these waters.

Water reservoirs also contribute to an actual loss of water from the hydrologic cycle by providing effective surfaces and time for evaporation. Although current research is being directed toward the development of means for minimizing these losses, any practicable technique will be responsible for a further increase in unit costs for water.

Reservoirs created for the purpose of water conservation become attractive for sports and other recreational uses. The pollutional significance of these activities is also being accelerated as a result of urbanization and as a consequence of the increase in time available for leisure activities and improvement of access to these areas. The utilization of reservoirs for recreation (swimming, fishing, and boating) is in direct conflict with conservation of these resources for water supply. Almost any level of recreational use of a reservoir and its drainage basin will be tolerable if the public is ready and willing to pay the increased cost for treating these waters prior to their use as a public water supply. Only a few years ago, conservationists were expressing great concern over municipal and industrial degradation of water resources which was interfering with recreational uses, while engineers and industrialists were proposing the concept of utilizing the capability of the receiving stream for accomplishing part of the job of waste treatment. The cycle may be completed when the conservationist-sportsman is kept from recreational use of watershed and reservoir areas because his activity will result in incremental pollution which cannot be tolerated.

Illustrative of the massive onslaught essential to make a substantial impact on present problems of water pollution is the recently made proposal by Governor Rockefeller for the state of New York. ${ }^{13} \mathrm{He}$ has called for a $\$ \mathrm{r} .7$ billion program to finance a six-year program of construction. These funds will be used to construct interceptor pipe lines and treatment plants to collect and treat wastes which are

\footnotetext{
${ }^{12}$ Fair, Protecting the Purity of Inland Waters, Proceedings of the AMerican Societry of Civn. ENGINEering (Journal of the Sanitary Engincering Division, Vol. 99, No. SA6, p. I, Dec. I964).

${ }^{10}$ N.Y. Times, Dec. 28, I964, $\$$ r, pp. I, 23.
} 
either not presently treated at all or poorly treated. These projects have little or no bearing on some of the major problems previously mentioned as requiring our present concern.

The magnitude of the present problem was expressed in a national municipal policy statement approved by the American Municipal Association and contained in the record of the Hearings of the Special Subcommittee on Air and Water Pollution of the Senate Committee on Public Works. ${ }^{14}$ In part, the statement contains the following description of our needs:

Nearly 3,600 new sewage treatment works are needed to serve 19 million persons living in communities that have never provided treatment for their wastes. Another 664 new plants are needed for 5 million persons in communities where treatment works have become overloaded or are obsolete. Still another $\mathrm{I}, 000$ communities require new units or processes in order to serve populations totalling more than 19 million. The removal of the backlog of needs during the present decade, together with additional facilities required because of population growth and obsolescence of existing works, will require an average annual investment of $\$ 600$ million. In addition, some 6,000 new industrial waste treatment plants are needed at a cost of $\$ 4.5$ billion.

It is both significant and important to note that the legislation with which the hearings before Senator Muskie's Committee were concerned contained the following purposes: ". . . to establish a positive national water pollution control policy of keeping waters as clean as possible as opposed to the negative policy of attempting to use the full capacity of such waters for waste assimilation."

\section{Water Pollution Research}

Although research is currently under way bearing directly on these problems, it is, to use a most appropriate figure of speech, a "drop in the bucket." In 1964, the Public Health Service expected to award $35^{8}$ grants amounting to $\$ 7,328,000$ to support research directed toward pollution control. ${ }^{15}$ A reasonable estimate of our total annual expenditure for research in water pollution control may be reached by doubling this figure to include research at all levels of government as well as private and industrial activity. This amounts to about $\$ 5$ million dollars per year or less than ten cents per capita per year for an "industry" that delivers and removes one thousand billion tons of water per year! This is an expenditure of $\$ 15$ for every million tons of product! Even this snail's pace of research in 1964 represents tremendously accelerated activity from what it was only six years ago when it was estimated that our total research efforts in water pollution control were at a level of $\$ 3.5$ million. What is obvious is that we have as a nation procrastinated away essential time necessary to develop pollution control technology to match our ever expanding ability to pollute our streams. We have done this at the expense of the

1s Hearings Before the Special Subcomm. on Air and Water Pollution of the Senate Comm. on Public Works, 88th Cong., rst Sess. 90 (1963).

${ }^{15}$ MeCallum, Water Pollution Control and Science-New Trends, Proceedings of THE THintrenth Southern Municipal and Industrial Waste CoNference 20 (1965). 
pollution absorbing capacity of our environment which now has reached almost saturation level in general and has long since exceeded saturation level in specific urban and rapidly urbanizing areas.

Although pollution control has been costly in the past, it is essential to recognize that our past expenditures and progress have been in the direction of solving our easiest problems. Waste treatment follows a pattern of greatly diminishing returns for equal dollar expenditures. A treatment process for achieving ninety per cent reduction of pollutional substances will generally have to be doubled in size and cost to achieve an incremental five per cent increase in efficiency. The next increment of two to three per cent will require an additional doubling of capital expenditure. Operational cost for each increment is likewise doubled and redoubled. A shocking, but realistic fact is that the quality of water we enjoy today is the highest quality we will ever experience. Quality can only be depressed in the future and costs for water of reduced quality must increase, both at a rapidly expanding rate.

Some idea of the ultimate value of our existing water resources might be projected from an as yet unachieved "break-through" price for fresh water produced from saline waters. The break-through price is that which is currently considered to be the aim of engineers investigating processes for economically removing soluble salts from water of marginal or unacceptable quality. It has been suggested that \$I per thousand gallons is within our technical and economic capability. This price reflects only a hopeful possibility, and does not include the cost of storage and distribution nor of collection and treatment. If our economic system could adjust itself to reflect such a price and if our demand would be in total unaltered from the existing level of usage, the economic value of our water today would be \$1ro billion dollars-an amount approximately equal to our present National Budget or onesixth of our Gross National Product. It is clear that readjustment of our economy to reflect such a change in the relative value of this commodity priced in accord with an alternative method for obtaining it from the oceans, if such a process emerges from our current research and development efforts, will require considerable changes in our judgment of values. It has been said that as a nation we can afford any degree of stream sanitation we choose. A consequence of the degree we choose will be the cost of its achievement.

\section{URBAN Growth aNd Water Resources}

The impact of urban growth the nation as a whole faces in the foreseeable future is present with us today in select regions of the United States. Florida and California are both growing in terms of gross population and experiencing the shift from rural to urban development patterns, both outstripping the current availability of water and wastewater utilities. For Florida, this pattern is revealed by $\mathrm{Lee}^{\mathbf{1 6}}$ in table two.

\footnotetext{
${ }^{10}$ Lee, Problems of Non-Urban Development, Procendings of The TeNTH Southern Municipal and Industrial Waste Conference is (196r).
} 
TABLE 2

\section{Florida Population, Urban and Rural} 1930, 1940, 1950, rg60

\begin{tabular}{|c|c|c|c|c|}
\hline & $\begin{array}{c}\text { Total } \\
\text { Population }\end{array}$ & $\begin{array}{c}\text { Urban } \\
\text { Population }\end{array}$ & $\begin{array}{l}\text { Percent } \\
\text { of Total }\end{array}$ & $\begin{array}{c}\text { Rural } \\
\text { Population }\end{array}$ \\
\hline 1960 & $4,95^{1,560}$ & $3,66 \mathrm{r}, 3^{8} 3$ & 73.9 & $\mathrm{I}, 290, \mathrm{I} 77$ \\
\hline r95o & $2,771,305$ & $1,8 r_{3}, 890$ & 65.5 & 957,415 \\
\hline 1940 & $x, 897,414$ & $\mathrm{x}, 045,79 \mathrm{r}^{*}$ & 55.1 & 851,623 \\
\hline I930 & $I, 468,2 \mathrm{II}$ & $759,77^{8}$ & 51.7 & 708,433 \\
\hline
\end{tabular}

* Between the 1950 and 1940 censuses, the Bureau of the Census changed its definition of urban population, which accounts for some of the increase from 1940 to 1950 . Under the old definition, the x950 urban population would have been $\mathrm{x}, 566,788$, or $56.5 \%$. The actual increase probably lies some. where between the two figures.

Illustrative of typical problems encountered in such rapid change in population characteristics are those cited by David B. Lee, Director of the Florida Bureau of Sanitary Engineering: ${ }^{17}$

Recognition of suburbia as a serious problem occurred in our state back in the early '5os when Congressman Rains and his committee held hearings in Jacksonville and Miami. Many actual environmental health hazards were documented. At about that time, we became successful in getting most of our subdivisions, particularly the large ones, to install water and waste treatment facilities.

The Florida State Board of Health attempted to face this growth by working with subdivision developments. When we required sanitary facilities, both water and waste, to be provided by builders and developers, the usual objections from them on the grounds that provision of sanitary facilities was a governmental function were received. However, despite normal resistance, we were fairly successful. Today, we have around $25^{\circ}$ or perhaps 300 sewage treatment works of rather large size in subdivisions and probably 600 or 700 water supply and treatment facilities.

At first, these were basically individual subdivisions. The developer, of course, was not able to project into the future, or didn't want to. Few projectors in the early '5os anticipated the actual growth pattern. The years rolled by with normal growth accelerated by the development of mass building. We attempted to get subdivisions and developments to put in facilities which others could join. This created a problem because many developers did not wish to have their water and sewer lines taken over or used by another developer or competitor.

The major problem has not been getting water supply and distribution, although in some areas we have quite a diffcult job in obtaining water of suitable quality for treatment. In general, our water problems are not nearly as bad as our waste problems.

Much urban development is peripheral to systems of organized water and sewer utilities. The immediate problem is often "solved" by construction of private wells and installation of septic tanks and drainage fields. The temporary nature of this

${ }^{17} 1$ bid. 
solution is a well documented story in all parts of this country. Great pressure is currently being applied for the extension of both water and wastewater utility systems to service peripheral areas. Our cities can scarcely keep up with the demand for additional facilities needed for their internal growth and reasonable annexation. Superimposition of utility extensions to service suburbia will be costly experiences. It will be excessively costly until legal systems are devised which will extract the full cost of water and wastewater utility extensions from the increase in land value resulting from the activities of the speculative land developers.

Despite its fundamental importance, there appears to be little hope for any immediate major change in the decision-making process involving land development. Few individuals purchasing homes out of reach of existing water utility systems give any consideration to the functional role and limitations of their private water and wastewater utility systems beyond insuring their immediate workability. The capital expenditure for a private well and septic tank system can be as much or more than that for these services within a municipality, while their life may be as short as several years, at which time an at least equal expenditure may be necessary for connection to extended services.

Of great urgency is the immediate development of legal tools, as for example, state, county, and municipal zoning with good technical consultation in their conception and enforcement. Implementation of technically sound subdivision regulations and their enforcement against a background of competent technical consultation are mandatory. Short term private gains must yield to long term public interest. The clearance of building and construction permits through the appropriate levels of health departments for adequate provision of water, waste facilities, and air pollution control is clearly needed immediately. These must not be token arrangements. Enforcement must be possible!

The future direction of progress toward the management of our water resources would logically appear to be in the organization of water resources authorities for both minor and major drainage basin. Such authorities as exemplified by the Genossenschaften or regional cooperative water resources associations of the Ruhr and Emscher valleys in Germany ${ }^{18}$ would have as their functional role the development of means for conducting multi-purpose water programs including the responsibility for abatement of pollution. The financing of such efforts would be on the basis of both influent and effluent charges and property taxation. It is conceivable that such an authority would construct and operate plants on our rivers for the purpose of replenishing the groundwater resources of the region, furnishing potable water for urban and industrial needs directly, regulating flows for maximum conservation of quantity for both water supply and waste dilution, operate plants for the improvement of stream water quality, and engage in basic and applied research on the water resources problems of the region.

\footnotetext{
${ }^{18}$ Okun, Aspects of European Water Management, Public Works, June 1962, p. III.
} 
The Ruhr and Emscher associations, formed more than fifty years ago, operate reservoirs for water supply, hydroelectric power plants, pumping stations, and waste treatment plants. Income is derived from all residing and operating manufacturing plants in the area served on the basis of their use of water and connection to collection systems. The interdependence of pollution control and water supply are recognized with all users who benefit from the consolidation and optimization bearing their proportional share of the cost.

\section{ConClusion}

We must approach the problems involving our water resources in view of our projected urban growth during the remainder of this century with great alarm. It cannot be over-emphasized that we are essentially living on borrowed time. Major efforts far over and above those presently being undertaken and planned must be made simply to keep the rate of increase of pollution of our air and water resources down to the minimum level possible while major efforts are underway to discover methods for solving our immediate and future problems.

Reorganization of our political boundaries to permit more effective utilization of regional water resources is imperative. Natural drainage channels which often function as political boundaries are basically unsuitable as jurisdictional limitations with regard to exercise of control over pollution. None of the eighteen major river basins of the continental United States are located within a single state and five are not located entirely within the United States.

Although the immediate problem can, and in fact must, be approached by physical redistribution of our total water resources within the changing patterns of relative economy, we must keep in mind that we are not basically solving the problem. We are only buying time in which to accomplish the necessary research, and during this time we must grapple with the fundamental technical aspects of the problem and develop suitable legal and political structures for implementing its solution. 